\title{
Relationship between Self-Rated Health and Lifestyle and Food Habits in Japanese High School Students
}

\author{
Tomoko Osera ${ }^{1,2}$, Mitsuyo Awai ${ }^{3}$, Misako Kobayashi ${ }^{2}$, Setsuko Tsutie ${ }^{4}$ and \\ Nobutaka Kurihara ${ }^{1, *}$ \\ 1 Hygiene and Preventive Medicine, Graduate School of Home Economics, Kobe Women's University, \\ 2-1 Higashisuma-Aoyama, Suma, Kobe 654-8585, Japan; tomokocup12@yahoo.co.jp \\ 2 Takakuradai Kindergarten attached to Kobe Women's University, 4-2 Takakuradai, Suma, Kobe 654-0081, \\ Japan; mkobayashi@suma.kobe-wu.ac.jp \\ 3 School of Nursing, Kansai University of Nursing and Health Science, 1456-4 Shizuki, Awaji-City 656-2131, \\ Japan; m.awai@kki.ac.jp \\ 4 Clinical Nutrition Management, Graduate School of Home Economics, Kobe Women's University, \\ 2-1 Higashisuma-Aoyama, Suma, Kobe 654-8585, Japan; tsuti@suma.kobe-wu.ac.jp \\ * Correspondence: kurihara@suma.kobe-wu.ac.jp; Tel.: +81-78-737-2417
}

Received: 29 August 2017; Accepted: 13 October 2017; Published: 18 October 2017

\begin{abstract}
Self-rated health (SRH), a subjective assessment of health status, is extensively used in the field of public health. It is an important and valid measure that is strongly related to morbidity, mortality, longevity and health status. Adolescence is a crucial period for the formation of health status, because health-risk behaviours (e.g., skipping breakfast) are often established during this period. In this study, we investigated the relationship of SRH with lifestyle and eating habits in Japanese high school students. In this study, 1296 students aged 16-18 years from 11 high schools in Japan participated. A questionnaire was administered to these participants that included a question on SRH, five questions on demographic characteristics, six questions on lifestyle items (e.g., wake-up time), five questions on miscellaneous health issues (e.g., anorexia), and 25 questions on food habits and attitudes towards food. We examined the differences between self-rated healthy and unhealthy groups using logistic regression analysis adjusted for gender and age. A dichotomy regression analysis was performed using a stepwise elimination method. Of the 1296 respondents, $16.7 \%$ reported feeling unhealthy, $57.7 \%$ of whom were females. The self-rated healthy group had a higher frequency of eating breakfast (odds ratio (OR): 2.13; confidence interval (CI): 1.07-4.24) and liked home meals to a greater extent (OR: 3.12; CI: 1.27-7.65) than the self-rated unhealthy group. The two groups did not differ significantly in terms of other lifestyle factors or unidentified complaints. Our results suggest that liking home meals during adolescence may lead to the development of good eating habits, i.e., eating breakfast, and better SRH.
\end{abstract}

Keywords: self-rated health (SRH); adolescence; cross-sectional study

\section{Introduction}

Self-rated health (SRH), a subjective assessment of health status, is extensively used in the field of public health. The validity of SRH measures, in terms of their ability to predict mortality risk, has been established in multiple studies [1]. The utility of SRH assessments has been shown in people with moderate-to-severe chronic kidney disease [2]. It is an important and valid measure, strongly related to morbidity, mortality, longevity and health status [1,2]. In addition, SRH is affected by several lifestyle, diet and biochemical factors [3,4].

Although SRH is a useful tool for estimating the subjective health needs of populations, some research has revealed that SRH may capture different aspects of the health of different social groups [5-7]. 
For example, blacks and whites may have different needs for health care compared to other population groups [8]. In addition, different profiles of social and behavioural determinants of SRH among patients with diabetes have been shown across countries [9]. Thus, local data is needed because of the considerable cross-racial, cross-ethnic, and cross-country variations in meanings and correlates of SRH.

Adolescence is a crucial period for the formation of health status [10-12]. Indeed, many health-related behaviours are formed during this period, including smoking, alcohol consumption, drug use, nutrition-related behaviours and physical activity [13]. During adolescence, health is also strongly affected by social factors, including income inequality, family support, school environment and peer influence [14].

SRH assessment among adolescents is a good measure of evaluating health-rated self-concepts. Specifically, SRH is strongly associated with general well-being and psychosomatic symptoms [11,15-17]. Research has suggested that SRH is influenced by gender, family support, lifestyle and psychological factors [13]. Moreover, one study has demonstrated a significant positive association between SRH and self-rated eating habits, suggesting that dietary habits influence overall perceived health [18]. However, there is a paucity of studies on SRH during adolescence. In addition, no study has shown a relationship between SRH and food habits of adolescents. Therefore, in this study, we investigated the association of SRH with lifestyle and eating habits in Japanese high school students.

\section{Materials and Methods}

\subsection{Design and Data Collection}

A cross-sectional study was conducted from May to November, 2015. In total, 1300 students aged 16-18 years from 11 high schools in Hyogo and Mie, Japan, participated in the study. The study areas were rural and urban. Of the total participants, 1296 (99.6\%) returned the completed questionnaire, and all provided informed consent.

The questionnaire comprised one question on SRH, five questions on demographic characteristics, six questions on lifestyle items (e.g., wake-up time, bedtime, sleeping habits and BMI), five questions on miscellaneous health issues (e.g., feel tired, anorexia, dizziness, become irritable and cephalalgia), and 25 questions on food habits and attitudes towards food (e.g., frequency of eating breakfast, concerns about food, respect for food, watching TV while eating and talking about food with family). Both 4- and 5-point rating scales were used, with higher scores indicating more positive food habits. For example, questions regarding 'respect for food' utilised a 5 -point rating scale $(5=$ high concern, $4=$ middle concern, 3 = concern, 2 = little concern, 1 = no concern).

\subsection{SRH Status}

Global SRH measures generally include a question such as 'How would you rate your overall health?' and offer five response categories that range from excellent to poor (i.e., excellent, very good, good, fair and poor) [19-21]. In this study, we grouped scores of the SRH variable into two categories: the 'healthy' group included the responses 'excellent' and 'very good', whereas the 'unhealthy' group included the responses 'good', 'fair' and 'poor'.

\subsection{Statistical Analyses}

The Chi-square test and Fisher's exact test were used to evaluate differences in independent variables and SRH between the groups. $T$-tests were used to compare each variable between the self-rated healthy and unhealthy groups $p$ values of $<0.05$ were considered to indicate statistically significant differences.

Variables that were significant in the bivariate analysis were included in a multivariable logistic regression analysis with SRH as the dependent variable. The model was adjusted for gender and age, and a stepwise elimination method was employed for variable selection. Data were entered and analysed using SPSS for Windows, version 23.0 (IBM, New York, NY, USA). 
Structural equation modelling was used to explore more complex food habit associations and alternative strategies for handling missing data. The following indices were used to assess model fit: goodness of fit index (GFI), adjusted goodness of fit index (AGFI), comparative fit index (CFI) and root-mean square error of approximation (RMSEA). Models were considered as having a good fit when values of GFI, AGFI and CFI were higher than 0.9, when the value of RMSEA was lower than 0.05 , and values of AIC and CAIC were smaller. Model fit was investigated using Amos software, version 6.0 (IBM, New York, NY, USA).

\subsection{Ethics Statement}

Participants were well informed about the objectives and methods of this investigation. They voluntarily participated in the questionnaire survey without any compulsion, and with the right to freely withdraw from the study. Individual privacy was strictly protected during the entire investigation. This study was approved by the Kobe Women's University Ethics Committee regarding Human Subjects.

\section{Results}

\subsection{Sample Characteristics and Item-Specific Responses}

Complete responses to the questionnaire items and sample characteristics are shown in Table 1. No statistically significant difference was observed between the two groups in terms of age, gender, grade, height, weight or BMI $(p>0.05$, Table 1$)$. In addition, there were no significant differences with regard to healthy vs. unhealthy or kind of school.

Table 1. Participant baseline characteristics classified by self-rated health $(n=1296)$.

\begin{tabular}{|c|c|c|c|c|c|c|}
\hline \multirow{2}{*}{\multicolumn{2}{|c|}{ Variable }} & \multicolumn{4}{|c|}{ Self-Rated Health } & \multirow[b]{2}{*}{$p$ Value } \\
\hline & & \multicolumn{2}{|c|}{ Very Good to Excellent } & \multicolumn{2}{|c|}{ Good to Poor } & \\
\hline \multirow{3}{*}{ Gender } & All & 1079 & $83.3 \%$ & 217 & $16.7 \%$ & \\
\hline & Male & 446 & $81.4 \%$ & 102 & $18.6 \%$ & N.S* \\
\hline & Female & 633 & $84.6 \%$ & 115 & $15.4 \%$ & N.S* \\
\hline \multirow[t]{3}{*}{ Grade } & Grade 2 & 449 & $41.6 \%$ & 97 & $44.7 \%$ & N.S* \\
\hline & Grade 3 & 630 & $58.4 \%$ & 120 & $55.3 \%$ & N.S* \\
\hline & Height (m) & 1043 & $162.5 \pm 8.5$ & 203 & $163.5 \pm 8.1$ & N.S ${ }^{+}$ \\
\hline \multirow[t]{3}{*}{ All } & Weight (kg) & 971 & $54.8 \pm 9.7$ & 190 & $55.4 \pm 10.6$ & N.S ${ }^{+}$ \\
\hline & BMI $\left(\mathrm{mg} / \mathrm{kg}^{2}\right)$ & 971 & $20.6 \pm 2.8$ & 190 & $20.6 \pm 3.1$ & N.S ${ }^{+}$ \\
\hline & Height (m) & 441 & $169.8 \pm 6.2$ & 98 & $169.7 \pm 5.7$ & N.S ${ }^{+}$ \\
\hline \multirow[t]{3}{*}{ Male } & Weight (kg) & 441 & $60.6 \pm 9.7$ & 96 & $60.6 \pm 11.3$ & N.S ${ }^{+}$ \\
\hline & BMI $\left(\mathrm{mg} / \mathrm{kg}^{2}\right)$ & 439 & $21.0 \pm 2.9$ & 96 & $21.0 \pm 3.5$ & N.S ${ }^{+}$ \\
\hline & Height (m) & 602 & $157.0 \pm 5.3$ & 105 & $157.7 \pm 5.3$ & N.S ${ }^{+}$ \\
\hline \multirow[t]{2}{*}{ Female } & Weight (kg) & 530 & $50.1 \pm 6.7$ & 94 & $50.1 \pm 6.5$ & N.S ${ }^{+}$ \\
\hline & BMI $\left(\mathrm{mg} / \mathrm{kg}^{2}\right)$ & 530 & $20.2 \pm 2.7$ & 94 & $20.1 \pm 2.5$ & N.S ${ }^{+}$ \\
\hline \multicolumn{7}{|c|}{ Bring Lunch Box } \\
\hline & None & 25 & $2.4 \%$ & 6 & $2.9 \%$ & \\
\hline & 4 times per week or less & 109 & $10.5 \%$ & 32 & $15.4 \%$ & N.S * \\
\hline & More than 5 times per week & 908 & $87.1 \%$ & 169 & $81.6 \%$ & \\
\hline
\end{tabular}

There were no significant differences between any subjects. Significance tested using chi-square ${ }^{*}$ test and $t$-test ${ }^{+}$.

\subsection{Relationships between SRH and Student's Food Habits/Attitude}

All variables related to lifestyle, food habit and attitude demonstrated statistically significant relationships (Table 2). The results suggested that positive lifestyle and food habits led to better SRH. In addition, the five variables related to miscellaneous health issues demonstrated a significant relationship with SRH (data not shown). 
Table 2. Representative items affected by self-rated health $(n=1296)$.

\begin{tabular}{|c|c|c|c|c|c|}
\hline \multirow[b]{3}{*}{ Sleeping habits } & \multicolumn{4}{|c|}{ Self-Rated Health } & \multirow{3}{*}{$p$ Value * } \\
\hline & \multicolumn{2}{|c|}{ Very Good to Excellent } & \multicolumn{2}{|c|}{ Good to Poor } & \\
\hline & $\mathrm{N}$ & $\%$ & $\mathrm{~N}$ & $\%$ & \\
\hline Less $4 \mathrm{~h}$ & 22 & $2.0 \%$ & 13 & $6 \%$ & \\
\hline Over $4-5 \mathrm{~h}$ & 152 & $14.1 \%$ & 42 & $19.4 \%$ & \\
\hline Over $5-6 \mathrm{~h}$ & 403 & $37.4 \%$ & 72 & $33.2 \%$ & $<0.001^{* * *}$ \\
\hline Over 6-7 h & 361 & $33.5 \%$ & 70 & $32.3 \%$ & \\
\hline Over $7-8 \mathrm{~h}$ & 135 & $12.5 \%$ & 14 & $6.5 \%$ & \\
\hline Over $9 \mathrm{~h}$ & 5 & $0.5 \%$ & 6 & $2.8 \%$ & \\
\hline \multicolumn{5}{|l|}{ Frequency of eating breakfast } & \multirow{5}{*}{$<0.001^{* * *}$} \\
\hline None & 80 & $7.4 \%$ & 40 & $18.4 \%$ & \\
\hline 1-2 times per week & 50 & $4.6 \%$ & 10 & $4.6 \%$ & \\
\hline 3-4 times per week & 60 & $5.6 \%$ & 17 & $7.8 \%$ & \\
\hline Over 5 times per week & 886 & $82.3 \%$ & 150 & $69.1 \%$ & \\
\hline \multicolumn{5}{|c|}{ Frequency of eating breakfast with their family } & \multirow{5}{*}{$<0.01^{* *}$} \\
\hline None & 428 & $40.2 \%$ & 117 & $53.9 \%$ & \\
\hline 1-2 times per week & 118 & $11.1 \%$ & 15 & $6.9 \%$ & \\
\hline 3-4 times per week & 94 & $8.8 \%$ & 11 & $5.1 \%$ & \\
\hline Over 5 times per week & 426 & $40.0 \%$ & 74 & $34.1 \%$ & \\
\hline \multicolumn{5}{|c|}{ Frequency of using convenience store } & \multirow{5}{*}{$<0.01^{* *}$} \\
\hline Every day & 43 & $4.0 \%$ & 15 & $6.9 \%$ & \\
\hline 3-4 times per week & 87 & $8.1 \%$ & 30 & $13.8 \%$ & \\
\hline $1-2$ times per week & 408 & $37.8 \%$ & 84 & $38.7 \%$ & \\
\hline None & 540 & $50.1 \%$ & 88 & $40.6 \%$ & \\
\hline \multicolumn{5}{|l|}{ Respect for food } & \multirow{6}{*}{$<0.000^{* * *}$} \\
\hline None & 2 & $0.2 \%$ & 1 & $0.5 \%$ & \\
\hline Low respect & 12 & $1.1 \%$ & 7 & $3.3 \%$ & \\
\hline Medium respect & 101 & $9.4 \%$ & 34 & $15.8 \%$ & \\
\hline High respect & 357 & $33.2 \%$ & 81 & $37.7 \%$ & \\
\hline Higher respect & 602 & $56.1 \%$ & 92 & $42.8 \%$ & \\
\hline \multicolumn{5}{|l|}{ Concern about food } & \multirow{6}{*}{$<0.01 * *$} \\
\hline None & 17 & $1.6 \%$ & 6 & $2.8 \%$ & \\
\hline Low Concern & 69 & $6.5 \%$ & 28 & $13.2 \%$ & \\
\hline Medium Concern & 204 & $19.1 \%$ & 44 & $20.8 \%$ & \\
\hline High Concern & 364 & $34.1 \%$ & 73 & $34.4 \%$ & \\
\hline Higher Concern & 414 & $38.8 \%$ & 61 & $28.8 \%$ & \\
\hline \multicolumn{5}{|l|}{ Liked home meal } & \multirow{6}{*}{$<0.000^{* * *}$} \\
\hline Disliked & 13 & $1.2 \%$ & 5 & $2.3 \%$ & \\
\hline Low liking & 55 & $5.1 \%$ & 22 & $10.3 \%$ & \\
\hline Medium liking & 193 & $18.0 \%$ & 54 & $25.4 \%$ & \\
\hline Liked a lot & 318 & $29.7 \%$ & 62 & $29.1 \%$ & \\
\hline Liked very much & 491 & $45.9 \%$ & 70 & $32.9 \%$ & \\
\hline
\end{tabular}

* Significance tested using Chi-square test and Fisher's exact probability test. Note. ${ }^{* *} p<0.01,{ }^{* * *} p<0.001$ by Fisher's exact probability test.

\subsection{Multiple Logistic Regression Analysis}

Results of the logistic regression showed that SRH was significantly positively associated with the frequency of eating breakfast and liking home meals (Table 3). In addition, these two items had a stronger relationship with SRH than the remaining lifestyle and miscellaneous health issues. 
Table 3. Means and $95 \%$ confidence intervals of food habits by self-rated health in high school students after covariate adjustment.

\begin{tabular}{cccc}
\hline & OR & $\mathbf{( 9 5 \% ~ C I ) ~}$ & $p$ Value \\
\hline Frequency of eating breakfast & 2.13 & $(1.07,4.24)$ & 0.031 \\
Liked home meals & 3.12 & $(1.27,7.65)$ & 0.013 \\
\hline
\end{tabular}

OR, Odds ratio; CI, confidence interval. Multiple regression analysis used a stepwise method, adjusted for gender and age. Frequency of eating breakfast increased if many students ate breakfast more frequently.

\subsection{Structural Equation Modelling}

Figure 1 displays the results of the structural equation model related to students' food habits. The overall model fit was very good: $\mathrm{CMIN}=0.083 ; \mathrm{CMIN} / \mathrm{DF}=0.083 ; \mathrm{GFI}=1.000 ; \mathrm{AGIF}=1.000$; NFI Delta $=0.999 ; \mathrm{CFI}=1.000 ; \mathrm{RMSEA}=<0.001 ; \mathrm{AIC}=10.083$ and $\mathrm{CAIC}=40.860$. In the structural equation model, SRH was associated with the frequency of eating breakfast and liking home meals. We defined 'liking home meals' as the observable variable of the latent variable 'attachment'. Likewise, we defined 'frequency of eating breakfast' as the observable variable of the latent variable 'morning habits'.

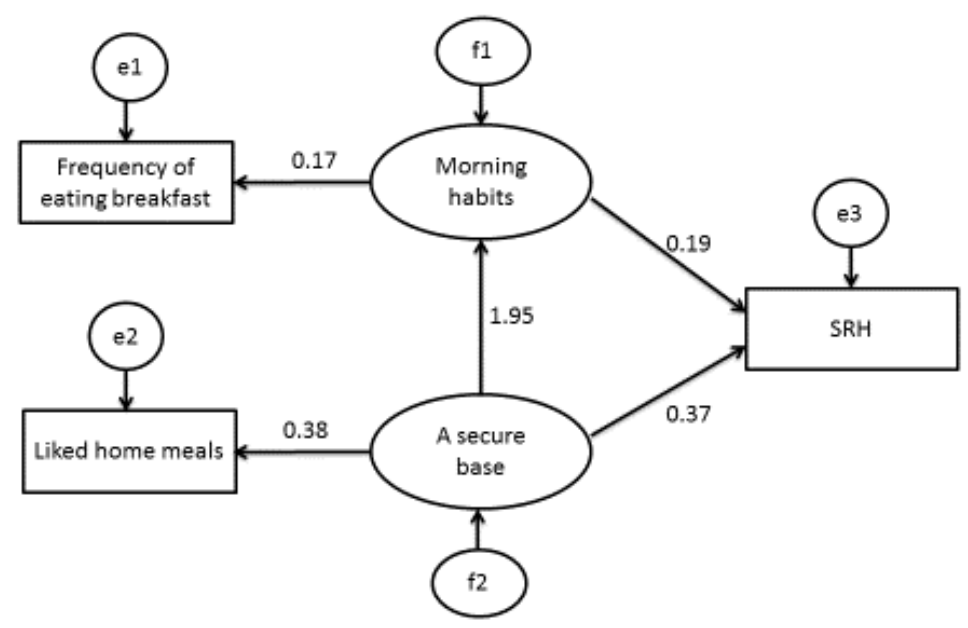

Figure 1. The structural equation model related to SRH and food habits $(n=1296)$. Note: Rectangles indicate observed variables and ovals indicate latent variables. Values of single arrowheads indicate standardised coefficients. All pathways are significant $(p<0.05)$. Self-rated health was associated with morning habits and a secure base.

\section{Discussion}

This research revealed that the frequency of eating breakfast and liking home meals was related to SRH in high school students. Each concept is discussed in detail in the following sections.

Table 3 suggests that 'frequency of eating breakfast' was associated with SRH. As mentioned in the Introduction section, SRH is related to the actual health status. The study revealed that male and female high school students who started smoking very early reported poorer SRH than students who had started later or had never smoked [22]. Based on these findings, it is suggested that SRH is the key factor for assessing the health of high school students.

Some research studies have suggested that the frequency of eating breakfast relates to the food habits and lifestyle patterns of adolescents. A decline in breakfast consumption has been reported during adolescence [23]. Furthermore, meal patterns, such as skipping breakfast, have been shown to be related to a group of less healthy lifestyle factors and food choices, leading to poorer nutrient intake [24]. Regular breakfast consumption has been associated with lower blood cholesterol and lower bodyweight [25]. Lastly, some studies have reported associations between skipping breakfast 
and increases in BMI or rates of metabolic syndrome [26,27]. Our results indicated that morning habits are a very important factor influencing the SRH of high school students, which may influence their future health.

In addition, our previous study clarified the association between food preferences and food habits of children, suggesting that morning habits have profound effects on concern and respect for food and food preferences [28]. In a study, it was concluded that breakfast contributes important nutrients to the diet of Australian children [29]. Our results indicated that morning habits may be related to health in adolescent students as well. Our results also indicated that sleeping habits were related to SRH (Table 2). Indeed, students with good sleeping habits (i.e., those who reported sleeping early and waking up early), may have sufficient time to eat breakfast every morning. Furthermore, people who had healthy lifestyles during childhood might more likely transfer healthy lifestyle patterns during adulthood to their own children in adulthood.

This study indicated that liking home meals was associated with SRH and morning habits. It has been shown that, during adolescence, the proportion of energy consumed at restaurants or fast-food establishments increases significantly, whereas that consumed at home decreases [30,31]. It is important to understand the factors that influence the preference of adolescents to eat at home rather than elsewhere. Watts et al. has described that targeting the home food environment is important to enable healthier food choices among overweight and obese adolescents [32]. In a study by Lee et al. [33] based on the Korea National Health and Nutrition Examination Survey, adults in the 'non-home-made meal group' tended to consume fried and grilled food, and had more one-dish meals, such as noodles and dumplings, compared with the 'home-made meal group'. According to our study results, liking home meals is very important in terms of food choices, and may be connected with overall health. In addition, the results of the structural equation model suggested that 'liking home meals' was affected by the frequency of eating breakfast. In brief, this means that, adolescents who like home meals may have good morning habits and sufficient time to eat breakfast.

The results of the logistic regression and the structural equation model showed that 'liking home meals' was related to SRH. One research group examined the family social environment in childhood and SRH in young adulthood, and its results showed that enhanced family cohesion, particularly after family disruptions during childhood, promotes health in young adulthood [34]. Thus, families, and especially mothers, must cooperate with their children's preferences regarding home meals. Mothers with higher SRH have a lower BMI [35]. Furthermore, the SRH in mothers is associated with their mothers'health. MacFarlane [36] has emphasized that parents should be encouraged to listen to and consider the food preferences of their adolescent children and provide supportive family mealtime environments and healthy foods at home. This argument is similar to our own. In addition, three of our previous studies have suggested that the attitudes of mothers towards food may have profound effects on children's food preferences [37-39]. The attitudes of mothers towards their children's diets may affect children's food preferences not only in childhood, but also in adolescence. 'Liking home meals' was associated with concern of mothers about their children's diet and health. This may be connected with Bowlby's secure base theory [40,41]. A secure base is very important for a child's healthy development. Adolescents who like home meals may have a good relationship with their parents at home. Thus, it is important that parents serve meals to their children so that children learn to like home meals. Above all, lifestyle factors, including mothers' concern about their children's diet, may be associated with the SRH of high school students.

In the current study, we assessed the relative importance of the lifestyles and food habits of students in their SRH via multiple regression analysis (Table 3). SRH was significantly related to the frequency of eating breakfast and liking home meals. In addition, this study analysed the associations between the SRH of students and healthy eating using structural equation modelling (Figure 1). The model showed that SRH was associated with the frequency of eating breakfast and liking home meals. Both the logistic regression analysis and the covariance structure analysis using structural equation modelling extracted the same two items-'frequency of eating breakfast' and 'liking home 
meals' - from a pool of several items. This confirmed that the reproducibility and reliability of the results are sufficient. This finding suggested that the SRH of high school students is a key factor in assessing their health. In conclusion, the results of this study can benefit high school students, mothers and children.

\section{Study Limitations}

Because we intentionally oversampled 11 schools, the sample analysed herein may not be nationally representative. Although it is very difficult to obtain nationally representative data, our results suggested the validity of this study in general. In addition, our findings are consistent with those of other researchers. As such, the results of this study may be useful for the future health of high school students and further life indices of mothers/children.

Our study had a cross-sectional design, and may only describe a temporary phenomenon. Nevertheless, this hypothesis needs to be tested in more depth. In future studies, we would like to analyse the results of interventions or cohort studies.

In addition, the study showed that SRH is associated with the frequency of eating breakfast, but it did not investigate the contents of breakfast. In a next study, we will investigate the contents of breakfast and their relationship with SRH.

\section{Conclusions}

SRH was strongly related to the frequency of eating breakfast and liking home meals among Japanese high school students. We demonstrated that these factors are very important because students reporting to frequently eat breakfast and like home meals had higher SRH. These students are more likely to have better health than other students. Therefore, students who like home meals during adolescence may also develop good morning habits and better SRH.

Acknowledgments: We thank all the students and the teachers at the high schools for their participation and cooperation with our questionnaire.

Author Contributions: T.O., S.T. and N.K. developed the standardised protocol and the structured questionnaire. M.K. and M.A. conducted the focus group research in the high school education setting. T.O. drafted the manuscript. All authors revised the article critically for important intellectual content and approved the final manuscript.

Conflicts of Interest: The authors declare no conflict of interest.

\section{Abbreviations}

$\begin{array}{ll}\text { SRH } & \text { Self-related health } \\ \text { CMIN } & \text { Column Minima } \\ \text { CMIN/DF } & \text { Column Minima Degrees of Freedom } \\ \text { GFI } & \text { Goodness of fit index } \\ \text { AGFI } & \text { Adjusted goodness of fit index } \\ \text { NFI Deltal } & \text { Normed Fit Index Deltal } \\ \text { CFI } & \text { Comparative fit index } \\ \text { RMSEA } & \text { Root-mean square error of approximation } \\ \text { AIC } & \text { Akaike's Information Criterion } \\ \text { CAIC } & \text { Consistent Akaike's Information Criterion } \\ \text { SD } & \text { Standard deviation } \\ \text { N.S. } & \text { Not significant }\end{array}$




\section{References}

1. Finch, B.K.; Hummer, R.A.; Reindl, M.; Vega, W.A. Validity of self-rated health among latino(a)s. Am. J. Epidemiol. 2002, 155, 755-759. [CrossRef] [PubMed]

2. Robinson-Cohen, C.; Hall, Y.N.; Katz, R.; Rivara, M.B.; Boer, I.H.; Kestenbaum, B.R.; Himmelfarb, J. Self-rated health and adverse events in CKD. Clin. J. Am. Soc. Nephrol. 2014, 9, 2044-2051. [CrossRef] [PubMed]

3. McClave, A.K.; Dube, S.R.; Strine, T.W.; Mkdad, A.H. Associations between health-rated quality of life and smoking status among a large sample of U.S. adults. Prev. Med. 2009, 48, 173-179. [CrossRef] [PubMed]

4. Yamada, C.; Moriyama, K.; Takahashi, E. Self-rated health as a comprehensive indicator of lifestyle-related health status. Enviorn. Health Prev. Med. 2012, 17, 457-462. [CrossRef] [PubMed]

5. Zajacova, A.; Dowd, J.B. Reliability of Self-rated health in US Adults. Am. J. Epidemiol. 2011, 174, $977-983$. [CrossRef] [PubMed]

6. Assari, S. Ethnic groups differ in how poor self-rated mental health reflects psychiatric disorders. J. Racial Ethn. Health Disparit. 2017, 14. [CrossRef] [PubMed]

7. Lankarani, M.M.; Assari, A. Demographic and socioeconomic determinants of physical and mental self-rated health across 10 ethnic groups in the United States. Int. J. Epidemiol. Res. 2017, 4, 185-193. [CrossRef]

8. Assari, S.; Lankarini, M.M.; Burgard, S. Black white difference in long term predictive power of self-rated health on all-cause mortality in United States. Ann. Epidemiol. 2017, 26, 106-114. [CrossRef] [PubMed]

9. Assari, S. Cross-country variation in additive effects of socio-economics, health behaviors, and comorbidities on subjective health of patients with diabetes. J. Diabetes Metab. Disord. 2014, 13, 36. [CrossRef] [PubMed]

10. Mechanic, D.; Hansell, S. Adolescent competence, psychological well-being, and self-assessed physical health. J. Health Soc. Behav. 1987, 28, 364-374. [CrossRef] [PubMed]

11. Vingilis, E.; Waed, T.; Seeley, J. Predictors of adolescent self-rated health. Analysis of the National Population Health Survey. Can. J. Public Health 2002, 93, 193-197. [PubMed]

12. Vingilis, E.; Wade, T.; Seeley, J. Predictors of adolescent health care utilization. J. Adolesc. 2007, 30, 773-800. [CrossRef] [PubMed]

13. Sharma, B.; Nam, E.W.; Kim, D.; Yoon, Y.M.; Kim, Y.; Kim, H.Y. Role of gender, family, lifestyle and psychological factors in salf-rated health among urban adolescents in Peru: A school-based cross-sectional survey. BMJ Open 2016, e010149. [CrossRef] [PubMed]

14. Viner, R.M.; Ozer, E.M.; Denny, S.; Marmot, M.; Resnick, M.; Fatusi, A.; Currie, C. Adolescence and the social determinants of health. Lancet 2012, 379, 1641-1652. [CrossRef]

15. Boardman, J.D. Self-rated health among US adolescents. J. Adolesc. Health 2006, 38, 401-408. [CrossRef] [PubMed]

16. Breidablik, H.J.; Meland, E.; Lydersen, S. Self-rated health in adolescence: A multifactorial composite. Scand. J. Public Health 2008, 36, 12-20. [CrossRef] [PubMed]

17. Piko, B.F. Self-perceived health among adolescents: The role of gender and psychosocial factors. Eur. J. Pediatr. 2007, 166, 701-708. [CrossRef] [PubMed]

18. Sharif, M.Z.; Rizzo, S.; Marino, E.; Belin, T.R.; Glik, D.C.; Kuo, A.A.; Ortega, A.N.; Prelip, M.L. The association between self-rated eating habits and dietary behaviour in two neighborhoods: Findings from Proyecto Mercado FRESCO. Prev. Med. Rep. 2016, 3, 270-275. [CrossRef] [PubMed]

19. Joffer, J.; Jerden, L.; Ohman, A.; Flacking, R. Exploring self-rated health among adolescents: A think-aloud study. BMC Public Health. 2016, 16, 156. [CrossRef] [PubMed]

20. Warnoff, C.; Lekander, M.; Hemmingsson, T.; Sorjonen, K.; Melin, B.; Andreasson, A. Is poor self-rated health associated with low-grade inflammation in 43110 late adolescent men of the general population? A cross-sectional study. BMJ Open 2016, 6, e009440. [CrossRef] [PubMed]

21. Wu, S.; Wang, R.; Zhao, Y.; Ma, X.; Wu, M.; Yan, X.; He, J. The relationship between self-rated health and objective health status: A population-based study. BMC Public Health 2013, 13, 320. [CrossRef] [PubMed]

22. Hansen, K.; Lindstrom, M.; Rosvall, M. Age at smoking initiation and self-rated health among second grade high school boys and girls in Scania, Sweden, a cross sectional study. BMC Public Health 2015, 15, 1143. [CrossRef] [PubMed]

23. Siega-Riz, A.M.; Popkin, B.M.; Carson, T. Trends in breakfast consumption for children in the United States from 1965 to 1991. Am. J. Clin. Nutr. 1998, 67, 748S-756S. [PubMed] 
24. Sjoberg, A.; Hallberg, L.; Hoglund, D.; Hulthen, L. Meal paggern, food choice, nutrient intake and lifestyle factors in the Goteborg adolescence study. Eur. J. Clin. Nutr. 2003, 57, 1569-1578. [CrossRef] [PubMed]

25. Ruxton, C.H.S.; Kirk, T.R. Breakfast: A review of associations with measures of dietary intake, physiology and biochemistry. Br. J. Nutr. 1997, 78, 199-213. [CrossRef] [PubMed]

26. Alexander, K.E.; Ventura, E.E.; Spruijt-Metz, D.; Weigensberg, M.J.; Goran, M.I.; Davis, J.N. Association of breakfast skipping with visceral fat and insulin indices in overweight Latino youth. Obesity 2009, 17, 1528-1533. [CrossRef] [PubMed]

27. Boutelle, K.; Neumark-Sztainer, D.; Story, M. Weight control behaviors among obese, overweight, and nonoverweight adolescents. J. Pediatr. Psychol. 2002, 27, 531-540. [CrossRef] [PubMed]

28. Osera, T.; Tsutie, S.; Kobayashi, M.; Kurihara, N. Associations between children's food preferences and food habits towards healthy eating in Japanese children. J. Child Adolesc. Behav. 2016, 4, 1000292. [CrossRef]

29. Fayet-Moore, F.; Kim, J.; Sritharan, N.; Petocz, P. Impact of breakfast skipping and breakfast choice on the nutrient intake and body mass index of Australian children. Nutrients 2016, 8, 487. [CrossRef] [PubMed]

30. Bauer, K.W.; Larson, N.I.; Nelson, M.C.; Story, M.; Neumark-Sztainer, D. Fast food intake among adolescents: secular and longitudinal trends from 1999 to 2004. Prev. Med. 2009, 3, 284-287. [CrossRef] [PubMed]

31. Nielsen, S.; Siega-Riz, A.; Popkin, B. Trends in energy intake in U.S. between 1977 and 1996: similar shifts seen across age groups. Obes. Res. 2002, 10, 370-378. [CrossRef] [PubMed]

32. Watts, A.W.; Lovato, C.Y.; Barr, S.; Hanning, R.M.; Masse, L.C. Experiences of overweight/obese adolescents in navigating their home food environment. Public Health Nutr. 2015, 18, 3278-3286. [CrossRef] [PubMed]

33. Lee, K.W.; Song, W.O.; Cho, M.S. Dietary quality differs by consumption of meals prepared at home vs. outside in Korean adults. Nutr. Res. Pract. 2016, 10, 294-304. [CrossRef] [PubMed]

34. Roustit, C.; Campoy, E.; Renahy, E.; King, G.; Parizot, I.; Chauvin, P. Family social environment in childhood and self-rated health in young adulthood. BMC Public Health 2011, 11, 949. [CrossRef] [PubMed]

35. McCurdy, K.; Kisler, T.; Gorman, K.S.; Metallinos-Katsaras, E. Food and health-related correlates of self-reported body mass index among low-income mothers of young children. J. Nutr. Educ. Behav. 2015, 47, 225-233. [CrossRef] [PubMed]

36. MacFarlane, A.; Crawford, D.; Worsley, A. Associations between parental concern for adolescent weight and the home food environment and dietary intake. J. Nutr. Educ. Behav. 2010, 42, 152-160. [CrossRef] [PubMed]

37. Osera, T.; Tsutie, S.; Kobayashi, M.; Kurihara, N. Relationship of mothers' food preferences and attitudes with children's preferences. Food Nutr. Sci. 2012, 3, 1461-1466. [CrossRef]

38. Osera, T.; Tsutie, S.; Kobayashi, M.; Kurihara, N. A retrospective study on the relationship of changes in likes/dislikes with food habits in 4- and 6-year-old children. Eur. J. Nutr. Food Saf. 2014, 4, 604-613. [CrossRef]

39. Osera, T.; Tsutie, S.; Kobayashi, M.; Segawa, Y.; Kajiwara, C.; Hashimoto, H.; Kurihara, N. The effect of mothers' and fathers' food preferences on children's preferences with their attitude. Eur. J. Nutr. Food Saf. 2016, 6, 93-100. [CrossRef]

40. Bowlby, J. A Secure Base: Parent-Child Attachment and Healthy Human Development; Basic Books: New York, NY, USA, 2008.

41. Bretherton, I. The origins of attachment theory: John Bowlby and Mary Ainsworth. Dev. Psychol. 1992, 28, 759-775. [CrossRef]

(C) 2017 by the authors. Licensee MDPI, Basel, Switzerland. This article is an open access article distributed under the terms and conditions of the Creative Commons Attribution (CC BY) license (http://creativecommons.org/licenses/by/4.0/). 